\title{
Enantioselective Nickel-Catalyzed anti-Carbometallative Cyclizations of Alkynyl Electrophiles Enabled by Reversible Alkenylnickel E/Z Isomerization
}

\author{
Christopher Clarke, ${ }^{\ddagger}$ Celia A. Incerti-Pradillos, ${ }^{\ddagger}$ and Hon Wai Lam* \\ School of Chemistry, University of Nottingham, University Park, Nottingham NG7 2RD, United Kingdom
}

Supporting Information

ABSTRACT: Nickel-catalyzed additions of arylboronic acids to alkynes, followed by enantioselective cyclizations of the alkenylnickel species onto tethered ketones or enones, are reported. These reactions are reliant upon the formal anti-carbonickelation of the alkyne, which is postulated to occur by the reversible $E / Z$ isomerization of an alkenylnickel species.

$\mathrm{T}$ ransition-metal catalysis is utilized extensively in organic synthesis to prepare compounds required for numerous applications such as drug discovery, agrochemistry, and materials science. Despite the diversity of known transition-metalcatalyzed reactions, they all operate using combinations of only a few elementary organometallic reaction steps. One of these is the 1,2-insertion of a $\pi$-unsaturated component into a metalelement bond, which, owing to strict stereoelectronic requirements, is syn-selective. When applied to the migratory insertion of an alkyne with an organometallic species, this prevailing stereochemical principle (Figure 1A, top) provides a reliable

A
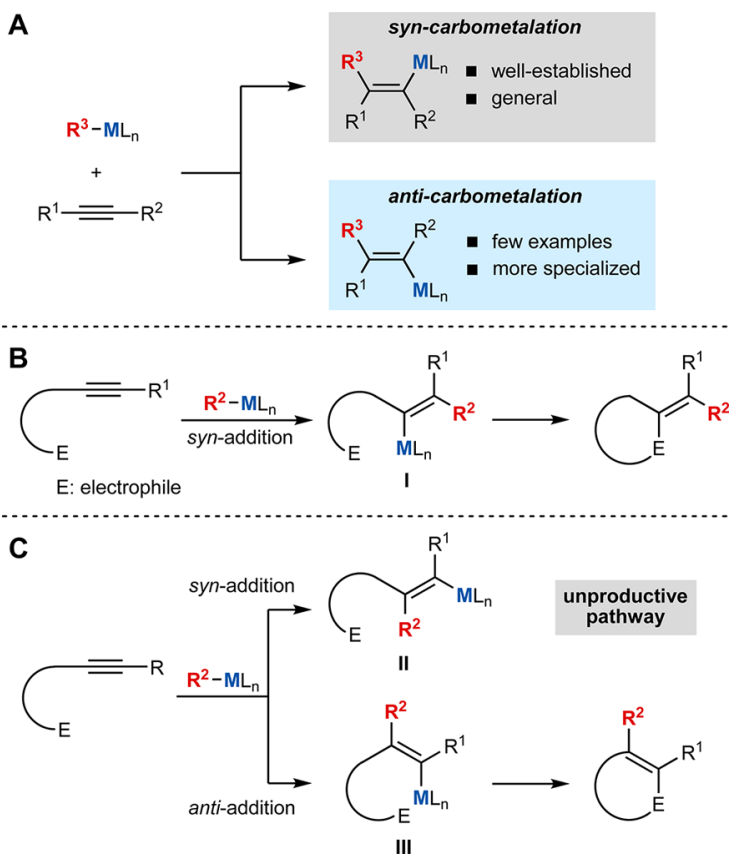

Figure 1. Carbometalation of alkynes and alkynyl electrophiles. route to stereodefined alkenes, a feature that has been exploited in numerous synthetic methods. ${ }^{1}$ Although anti-selective alkyne carbometalations (Figure 1A, bottom) would offer valuable new synthetic opportunities, such processes are uncommon. ${ }^{2}$

One strategy to obtain alkenylmetal species resulting from formal anti-carbometalation is to employ substrates with a heteroatom-containing substituent in close proximity to the alkyne. After syn-carbometalation, $E / Z$ isomerization to the antiisomer is driven by the formation of a more stable, chelated alkenylmetal species, in which the metal is coordinated to the heteroatom. $^{1 \mathrm{~b}, 2 \mathrm{a}, \mathrm{b}, \mathrm{d}, \mathrm{h}}$ Although effective, the requirement for a nearby heteroatom-containing group limits broader applicability. Other reactions that provide anti-carbometalation products proceed via alternative mechanisms involving radical intermediates, but the substrates are restricted to terminal alkynes. ${ }^{2 j-n, 3}$ In addition, with only a few exceptions, ${ }^{2 h, 1-n}$ both of the aforementioned approaches require stoichiometric quantities of more reactive organometallics such as Grignard or organozinc reagents, which limit functional group compatibility and require rigorous exclusion of air and moisture. Furthermore, the integration of these processes into enantioselective reactions has not been reported. Given these issues, developing new platforms to access alkenylmetal species derived from anticarbometalation of a wider range of alkynes, using organometallic reagents that exhibit high functional group tolerance, and in a manner that is amenable to asymmetric catalysis, would likely be of broad impact. Here, we describe enantioselective nickelcatalyzed domino alkyne carbometalation-cyclizations in which the products are derived from formal anti-carbonickelation of the alkyne. The reactions use simple internal aryl-substituted alkynes and air- and moisture-stable arylboronic acids.

This study arose when we became interested in the enantioselective domino addition-cyclization of alkynyl electrophiles (Figure 1B), which are valuable complexity-generating transformations. ${ }^{4}$ These reactions involve the syn-1,2-addition of an organometallic species across an alkyne to place the metal proximal to the electrophile (as in I), which enables cyclization to take place. ${ }^{5}$ However, if syn-carbometalation proceeds to place the metal distal to the electrophile (as in II), cyclization is not possible due to geometric constraints (Figure 1C). ${ }^{6}$ An anticarbometalation of the alkyne would provide a solution to this problem, as now the resulting alkenylmetal species III possesses the correct geometry for cyclization (Figure 1C). However,

Received: April 25, 2016

Published: June 22, 2016 
overcoming the inherent syn-selectivity of alkyne migratory insertion is a considerable challenge.

A previous study has shown that the stoichiometric addition of organonickel complexes to simple alkynes that do not contain a nearby heteroatom-containing functional group can lead to alkenylnickel species resulting from formal anti-addition, although not always exclusively. ${ }^{2 c}$ A single example of the cobalt-catalyzed addition of an arylboronic acid to a symmetrical dialkyl alkyne to give a trisubstituted alkene as a 1:1 mixture of $E$ / $Z$ isomers has also been reported. ${ }^{2 h}$ In each case, the authors propose an initial syn-addition across the alkyne followed by reversible $E / Z$ isomerization to give products of overall antiaddition. ${ }^{2 c, h}$ Despite the potential significance of these findings, more widespread applications to organic synthesis, such as addressing the gap in methodology outlined in Figure 1C, have yet to be reported.?

We began by reacting alkynone 1 a with $\mathrm{PhB}(\mathrm{OH})_{2}$ (2.0 equiv) in the presence of various cobalt and nickel salts, with or without added ligands. These experiments revealed that nickel catalysis gave promising results. For example, $\mathrm{Ni}(\mathrm{OAc})_{2} \cdot 4 \mathrm{H}_{2} \mathrm{O}(10 \mathrm{~mol}$ $\%)$ by itself was effective in promoting anti-arylmetallative cyclization at $80{ }^{\circ} \mathrm{C}$ in $\mathrm{MeCN} / 2-\mathrm{MeTHF}$ (3:2) to give 5,5bicycle $2 \mathrm{a}$ in $39 \%$ NMR yield (Table 1 , entry 1 ). ${ }^{8}$ Arylative

Table 1. Evaluation of Reaction Conditions ${ }^{a}$

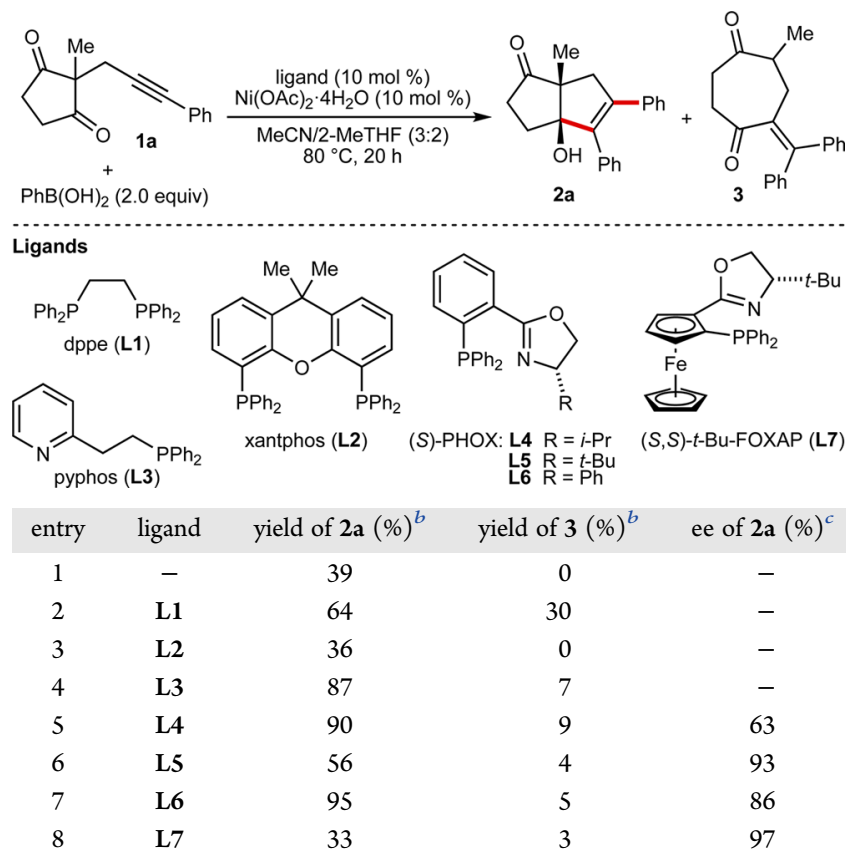

${ }^{a}$ Reactions employed $0.10 \mathrm{mmol}$ of $1 \mathbf{1 a} .{ }^{b}$ Determined by ${ }^{1} \mathrm{H}$ NMR analysis of the crude reactions, using 1,3,5-trimethoxybenzene as an internal standard. ${ }^{c}$ Determined by chiral HPLC analysis.

cyclization via 1,4-metal migration, as we have described using iridium catalysis, ${ }^{9}$ was not observed. Although the addition of dppe (L1) increased the NMR yield of $\mathbf{2 a}$ to $64 \%$, an appreciable quantity of the ring-expansion product 3 was also formed, which is derived from arylnickelation of the alkyne of $1 \mathrm{a}$ with the regioselectivity opposite to that seen in the formation of $\mathbf{2 a}$ (entry 2). ${ }^{9,10}$ Xantphos (L2) was inferior to dppe (L1) (entry 3), but the $P, N$-ligand $\mathbf{L} 3$ was much more effective and gave $\mathbf{2 a}$ in $87 \%$ NMR yield with only a small quantity of 3 (entry 4 ). Furthermore, by using commercially available chiral phosphinooxazoline ligands ${ }^{11}$ L4-L7, 2a was obtained in $63-97 \%$ ee (entries 5-8). Ligands L5 and L7 gave the highest enantioselectivities but the yields were modest (entries 6 and 8). (S)-Ph-Phox (L6) gave the best balance of yield and enantioselectivity (entry 7).

The scope of this process was then examined using $(R)-\mathrm{Ph}$ Phox (ent-L6) as the ligand (Table 2). By variation of the

Table 2. Scope of Five-Membered Cyclic 1,3-Diketones ${ }^{a}$

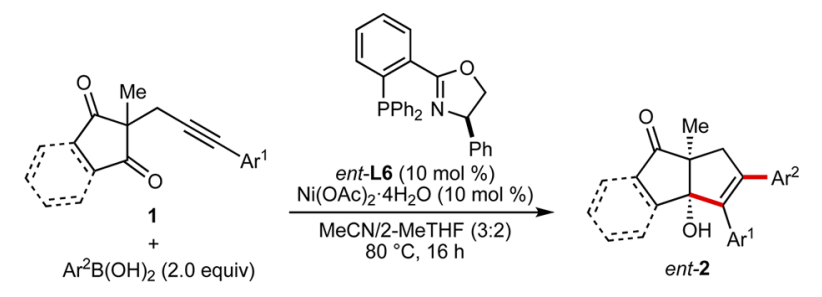

Arylboronic acid scope:

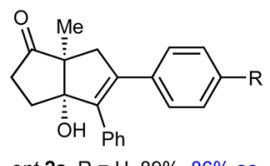

ent-2a $\mathrm{R}=\mathrm{H}, 89 \%, 86 \%$ ee

ent-2b R $=$ OMe, $70 \%, 77 \%$ ee ent-2c $\mathrm{R}=\mathrm{Cl}, 74 \%, 85 \%$ ee
ent-2d $\mathrm{R}=\mathrm{Ac}, 57 \%, 88 \%$ ee
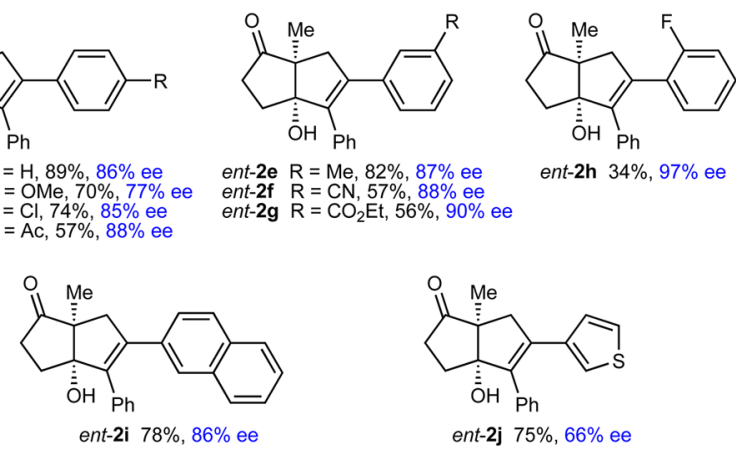

ent-2e $\mathrm{R}=\mathrm{Me}, 82 \%, 87 \%$ ee
ent-2f $\mathrm{R}=\mathrm{CN}, 57 \%, 88 \%$ ee ent-2g R $=\mathrm{CO}_{2} \mathrm{Et}, 56 \%, 90 \%$ e

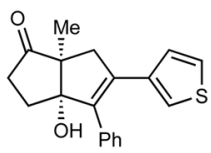

ent-2j $75 \%, 66 \%$ ee

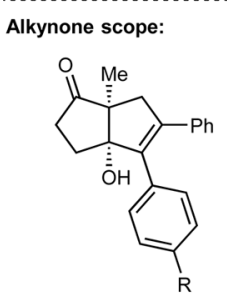

ent-2k $\mathrm{R}=\mathrm{OMe}, 68 \%, 85 \%$ ee ent-2l $\mathrm{R}=\mathrm{Cl}, 45 \%, 87 \%$ ee

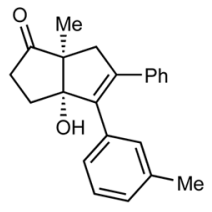

ent-2m $70 \%, 86 \%$ ee

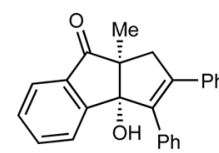

ent-2n $70 \%, 42 \%$ ee
${ }^{a}$ Reactions employed $0.30 \mathrm{mmol}$ of 1 . Yields are of isolated products. Enantiomeric excesses were determined by chiral HPLC analysis.

arylboronic acid and alkynone, products ent-2a-2n were obtained in $34-89 \%$ yield and $42-97 \%$ ee. The reaction is compatible with para- (ent-2a-2d), meta- (ent-2e-2g), and ortho-substituted (ent-2h) arylboronic acids, and the functional group tolerance is shown by examples with methoxy (ent-2b), halide (ent-2c and ent-2h), acetyl (ent-2d), nitrile (ent-2f), or carboethoxy (ent-2g) substituents. 2-Naphthylboronic acid (ent$2 \mathbf{i})$ and a heteroarylboronic acid (ent-2j) are also tolerated. Variation of the alkynyl substituent to other aryl groups is possible (ent-2k-2m), but terminal alkynes provide complex mixtures of unidentified products. Use of an indan-1,3-dionecontaining substrate gave ent-2n in $70 \%$ yield but in $42 \%$ ee. No reaction was observed using alkenylboronic acids or with substrates containing alkynes bearing methyl or trimethysilyl groups in place of aryl groups. ${ }^{12}$

When the cyclic 1,3-diketone was changed to a cyclohexane1,3-dione, significant dehydration of the initial cyclization products to give 1,3-dienes 5 was observed. The unpurified mixtures were therefore treated with $20 \% \mathrm{H}_{2} \mathrm{SO}_{4}$ in $\mathrm{AcOH}$ to drive dehydration to completion (Table 3). Using this procedure, substrates 4 with various substituents at the alkyne 
and the 2-position of the cyclohexane-1,3-dione gave dienes 5a5f in $37-79 \%$ yield and $88-97 \%$ ee.

Table 3. Scope of Six-Membered Cyclic 1,3-Diketones ${ }^{a}$

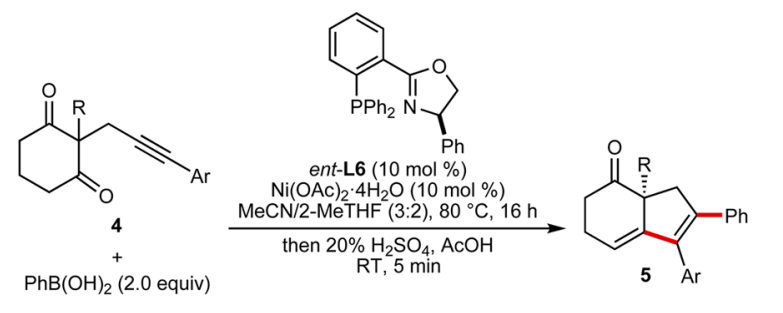

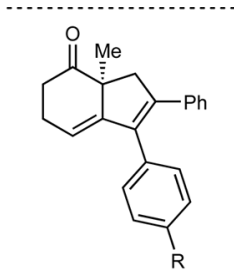

5a $\mathrm{R}=\mathrm{H}, 74 \%, 95 \%$ ee 5b $R=O M e, 56 \%, 97 \%$ ee
5c $R=C l, 37 \%, 95 \%$ ee

${ }^{a}$ Reactions employed $0.30 \mathrm{mmol}$ of 4 . Yields are of isolated products. Enantiomeric excesses were determined by chiral HPLC analysis.

Notably, this process is not limited to cyclic 1,3-diketones as the electrophilic trap, as substrates containing alkynes tethered to a cyclohexa-1,3-dienone are also highly effective (Table 4). For example, various arylboronic acids reacted with $6 \mathrm{a}\left(\mathrm{R}=\mathrm{Me}, \mathrm{Ar}^{1}\right.$ $=\mathrm{Ph})$ to give 6,6 -bicycles $7 \mathrm{a}-7 \mathbf{i}$ in $20-90 \%$ yield and $69-97 \%$

Table 4. Scope of Alkynyl Cyclohexa-1,3-dienones ${ }^{a}$
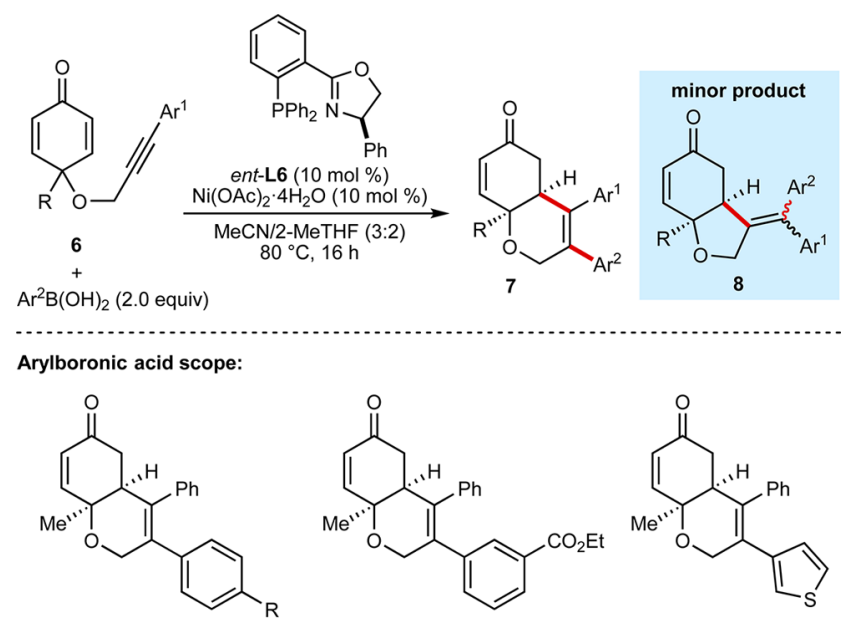

7a $\mathrm{R}=\mathrm{H}, 84 \%(7: 1), 94 \%$ ee 7b $\mathrm{R}=\mathrm{Me}, 86 \%(8: 1), 96 \%$ ee
7 c $\mathrm{R}=\mathrm{Ac}, 88 \%,(9: 1), 93 \%$ ee

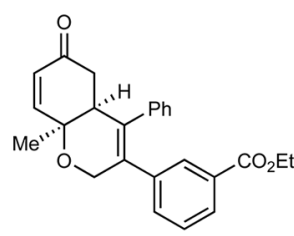

7d $75 \%(7: 1), 93 \%$ ee

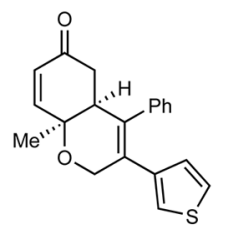

7e $87 \%(9: 1), 92 \%$ ee

Alkynyl cyclohexa-1,3-dienone scope:

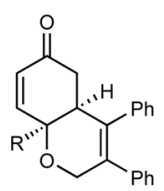

$7 f \mathrm{R}=\mathrm{Et}, 64 \%(6: 1), 97 \%$ ee $\begin{array}{ll}7 f & R=E t, 64 \%(6: 1), 97 \% \text { ee } \\ 7 g & R=P h, 20 \%(10: 1), 69 \% \text { ee }\end{array}$

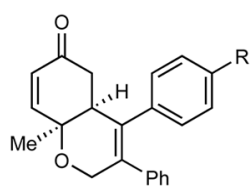

7h $\mathrm{R}=\mathrm{OMe}, 90 \%(6: 1), 91 \%$ ee $7 \mathrm{i} R=\mathrm{CN}, 83 \%(6: 1), 95 \% \mathrm{ee}$
${ }^{a}$ Reactions employed $0.30 \mathrm{mmol}$ of 6 . Yields are of isolated products. Ratios in parentheses refer to the ratio of 7:8 as determined by ${ }^{1} \mathrm{H}$ NMR analysis after purification. Enantiomeric excesses are of the major products $\mathbf{7 a - 7 i}$ as determined by chiral HPLC analysis. ee. These products were isolated together with small quantities of minor products $\mathbf{8}$, which result from arylnickelation of the alkyne with the regioselectivity opposite to that seen in the formation of the major products 7 . Changing the substituent at the quaternary center $(\mathbf{7} \mathbf{f}$ and $\mathbf{7 g})$ or the alkyne $(\mathbf{7 h}$ and $\mathbf{7 i})$ is also possible.

To gain insight into the mechanism of these reactions, the reaction of 1-phenyl-1-butyne with 4-methoxyphenylboronic acid in the presence of 1.0 equiv each of $\mathrm{Ni}(\mathrm{OAc})_{2} \cdot 4 \mathrm{H}_{2} \mathrm{O}$ and $\mathrm{L} 3$ was conducted (eq 1). This experiment gave trisubstituted alkene

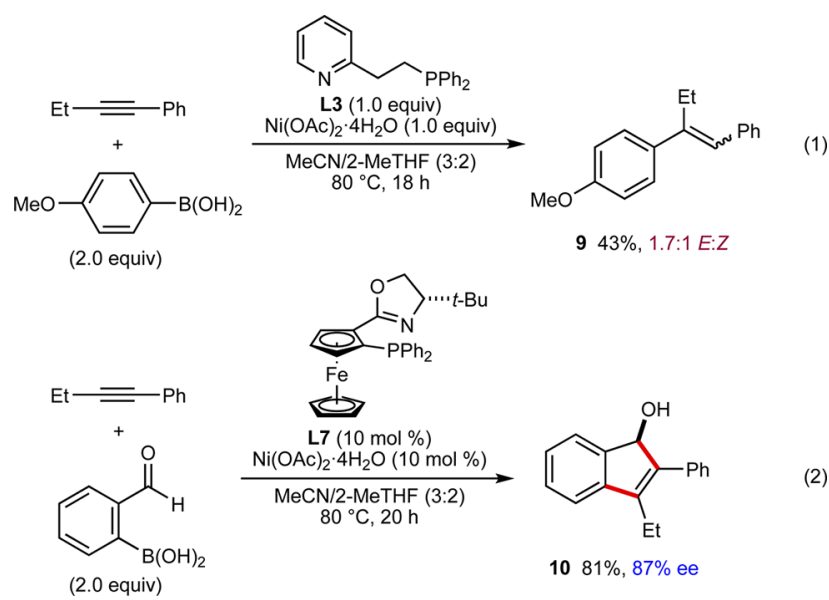

9 as a 1.7:1 mixture of $E$ - and Z-isomers, respectively, along with traces of isomers derived from arylnickelation with the opposite regioselectivity. As well as demonstrating the ability of nickel catalysis to provide anti-carbometalation products from alkynes that do not contain a tethered electrophile, this experiment suggests that the domino reactions described herein proceed through a mechanism similar to that shown in Figure 1C, rather than one involving initial "anti-Wacker-type" additions. ${ }^{6}$ The reaction of 1-phenyl-1-butyne with 2-formylphenylboronic acid using $\mathbf{L} 7$ as the chiral ligand (see Table 1, entry 8 for the use of $\mathbf{L} 7$ in anti-carbometallative cyclization) gave indene 10 in $81 \%$ yield and $87 \%$ ee (eq 2), which is a product of syn-arylnickelation of the alkyne followed by cyclization of the resulting alkenylnickel species onto the aldehyde. ${ }^{13}$ The ability to obtain enantioenriched products from either syn- or anti-carbometallative cyclization illustrates the adaptive power of this nickel-based catalytic system and further suggests that reversible $E / Z$ isomerization of alkenylnickel species is operative.

On the basis of these experiments, we propose a catalytic cycle for a representative example of anti-carbometallative cyclization, using alkynone 1a with $\mathrm{PhB}(\mathrm{OH})_{2}$ (Scheme 1). Transmetalation of $\mathrm{PhB}(\mathrm{OH})_{2}$ with the nickel complex 11 formed from $\mathrm{Ni}(\mathrm{OAc})_{2} \cdot 4 \mathrm{H}_{2} \mathrm{O}$ and ent-L6 gives an arylnickel species 12. Synarylnickelation of $\mathbf{1 a}$ with $\mathbf{1 2}$ gives the alkenylnickel intermediate $(Z)-13$, which can undergo reversible $E / Z$ isomerization, ${ }^{2 c, 14}$ to give a new alkenylnickel species $(E)-13$. Cyclization of $(E)-13$ onto one of the ketones gives nickel alkoxide 14, which can undergo protonolysis with water to release the product $\mathbf{2 a}$ and regenerate nickel complex 11 . Presumably, cyclization drives the equilibrium between $(Z)-13$ and $(E)-13$ toward the $E$-isomer. We assume a similar pathway is operative in the cyclizations of alkynyl cyclohexa-1,3-dienones (Table 4), with protonation of the nickel enolate formed by intramolecular 1,4-addition of the intermediate alkenylnickel species being the likely catalyst turnover step.

In conclusion, we have established that products of formal anti-carbometalation of alkynes can be obtained by exploiting the 


\section{Scheme 1. Postulated Catalytic Cycle}

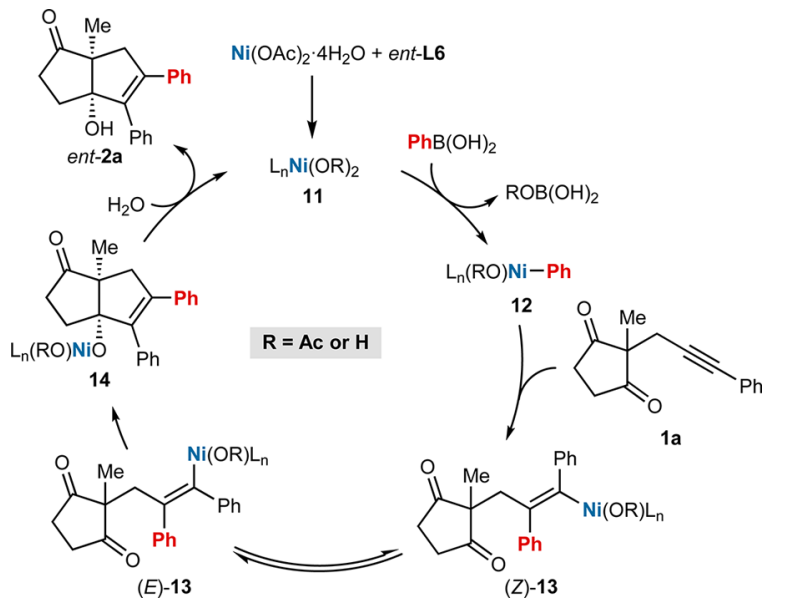

ability of alkenylnickel intermediates to undergo reversible $E / Z$ isomerization and have demonstrated the utility of this method in promoting previously inaccessible domino reactions with high enantioselectivities. We expect this underexplored mode of reactivity may have significant untapped potential, and its creative use in other contexts may lead to further new applications in organic synthesis.?

\section{ASSOCIATED CONTENT}

\section{S Supporting Information}

The Supporting Information is available free of charge on the ACS Publications website at DOI: 10.1021/jacs.6b04206.

Experimental procedures and full spectroscopic data for all new compounds (PDF)

Crystallographic data (CIF)

Crystallographic data (CIF)

Crystallographic data (CIF)

Crystallographic data (CIF)

\section{AUTHOR INFORMATION}

\section{Corresponding Author}

*hon.lam@nottingham.ac.uk

\section{Author Contributions}

${ }^{\ddagger}$ These authors contributed equally.

Notes

The authors declare no competing financial interest.

\section{ACKNOWLEDGMENTS}

We thank the ERC (Starting Grant no. 258580), EPSRC (Leadership Fellowship to H.W.L.; grants EP/I004769/1 and

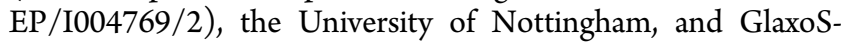
mithKline for support of this work. We thank Dr. Benjamin M. Partridge (University of Sheffield) for helpful suggestions. We are grateful to Dr. William Lewis (University of Nottingham) for X-ray crystallography.

\section{REFERENCES}

(1) For reviews, see: (a) Normant, J. F.; Alexakis, A. Synthesis 1981, 1981, 841. (b) Fallis, A. G.; Forgione, P. Tetrahedron 2001, 57, 5899. (c) Marek, I.; Chinkov, N.; Banon-Tenne, D. Carbometallation Reactions; Wiley-VCH Verlag GmbH: Weinheim, 2008. (d) Ding, A.; Guo, H. In Comprehensive Organic Synthesis II, 2nd ed.; Knochel, P., Ed.; Elsevier: Amsterdam, 2014; pp 891-938.
(2) (a) Jousseaume, B.; Duboudin, J.-G. J. Organomet. Chem. 1975, 91, C1. (b) Duboudin, J. G.; Jousseaume, B.; Saux, A. J. Organomet. Chem. 1979, 168, 1. (c) Huggins, J. M.; Bergman, R. G. J. Am. Chem. Soc. 1981, 103, 3002. (d) Ma, S.; Negishi, E.-i. J. Org. Chem. 1997, 62, 784. (e) Jia, C.; Lu, W.; Oyamada, J.; Kitamura, T.; Matsuda, K.; Irie, M.; Fujiwara, Y. J. Am. Chem. Soc. 2000, 122, 7252. (f) Lu, Z.; Ma, S. J. Org. Chem. 2006, 71, 2655. (g) Fressigné, C.; Girard, A.-L.; Durandetti, M.; Maddaluno, J. Angew. Chem., Int. Ed. 2008, 47, 891. (h) Lin, P.-S.; Jeganmohan, M.; Cheng, C.-H. Chem. - Eur. J. 2008, 14, 11296. (i) Yang, Y.; Wang, L.; Zhang, J.; Jin, Y.; Zhu, G. Chem. Commun. 2014, 50, 2347. (j) Cheung, C. W.; Zhurkin, F. E.; Hu, X. J. Am. Chem. Soc. 2015, 137, 4932. (k) Cheung, C. W.; Hu, X. Chem. - Eur. J. 2015, 21, 18439. (1) Li, Z.; García-Domínguez, A.; Nevado, C. J. Am. Chem. Soc. 2015, 137, 11610. (m) He, Y.-T.; Wang, Q.; Li, L.-H.; Liu, X.-Y.; Xu, P.-F.; Liang, Y.-M. Org. Lett. 2015, 17, 5188. (n) Li, Z.; García-Domínguez, A.; Nevado, C. Angew. Chem., Int. Ed. 2016, 55, 6938.

(3) After the submission of this paper, a palladium-catalyzed anticarboperfluoroalkylation of internal alkynes was reported: Domański, S.; Chaładaj, W. ACS Catal. 2016, 6, 3452.

(4) (a) Shintani, R.; Okamoto, K.; Otomaru, Y.; Ueyama, K.; Hayashi, T. J. Am. Chem. Soc. 2005, 127, 54. (b) Miura, T.; Shimada, M.; Murakami, M. J. Am. Chem. Soc. 2005, 127, 1094. (c) Miura, T.; Sasaki, T.; Nakazawa, H.; Murakami, M. J. Am. Chem. Soc. 2005, 127, 1390. (d) Shintani, R.; Tsurusaki, A.; Okamoto, K.; Hayashi, T. Angew. Chem., Int. Ed. 2005, 44, 3909. (e) Song, J.; Shen, Q.; Xu, F.; Lu, X. Org. Lett. 2007, 9, 2947. (f) Han, X.; Lu, X. Org. Lett. 2010, 12, 108. (g) He, Z.-T.; Tian, B.; Fukui, Y.; Tong, X.; Tian, P.; Lin, G.-Q. Angew. Chem., Int. Ed. 2013, 52, 5314. (h) Keilitz, J.; Newman, S. G.; Lautens, M. Org. Lett. 2013, 15, 1148. (i) Li, Y.; Xu, M.-H. Org. Lett. 2014, 16, 2712. (j) Johnson, T.; Choo, K.-L.; Lautens, M. Chem. - Eur. J. 2014, 20, 14194.

(5) For selected examples of enantioselective, transition-metalcatalyzed addition-cyclizations of alkynyl electrophiles that proceed through metallacyclic intermediates, see: (a) Rhee, J. U.; Krische, M. J. J. Am. Chem. Soc. 2006, 128, 10674. (b) Tanaka, R.; Noguchi, K.; Tanaka, K. J. Am. Chem. Soc. 2010, 132, 1238. (c) Masuda, K.; Sakiyama, N.; Tanaka, R.; Noguchi, K.; Tanaka, K. J. Am. Chem. Soc. 2011, 133, 6918. (d) Fu, W.; Nie, M.; Wang, A.; Cao, Z.; Tang, W. Angew. Chem., Int. Ed. 2015, 54, 2520.

(6) For nonenantioselective palladium-catalyzed domino cyclizationadditions of alkynyl electrophiles that proceed by "anti-Wacker" additions, see: (a) Tsukamoto, H.; Ueno, T.; Kondo, Y. J. Am. Chem. Soc. 2006, 128, 1406. (b) Tsukamoto, H.; Ueno, T.; Kondo, Y. Org. Lett. 2007, 9, 3033. (c) Tsukamoto, H.; Kondo, Y. Angew. Chem., Int. Ed. 2008, 47, 4851 .

(7) After the submission of this paper, a nickel-catalyzed anticarbometallative cyclization of alkynyl nitriles was reported: Zhang, X.; Xie, X.; Liu, Y. Chem. Sci., 2016, 7, Advance Article, 10.1039/ C6SC01191H.

(8) The relative and absolute configurations of the products were assigned by analogy with those of ent-2c, ent-2i, $7 \mathbf{a}$, and $\mathbf{1 0}$ which were determined by X-ray crystallography. See the SI for details.

(9) Partridge, B. M.; Solana González, J.; Lam, H. W. Angew. Chem., Int. Ed. 2014, 53, 6523.

(10) Miura, T.; Shimada, M.; Murakami, M. Angew. Chem., Int. Ed. 2005, 44, 7598.

(11) (a) von Matt, P.; Pfaltz, A. Angew. Chem., Int. Ed. Engl. 1993, 32, 566. (b) Sprinz, J.; Helmchen, G. Tetrahedron Lett. 1993, 34, 1769. (c) Allen, J. V.; Coote, S. J.; Dawson, G. J.; Frost, C. G.; Martin, C. J.; Williams, J. M. J. J. Chem. Soc., Perkin Trans. 1 1994, 2065.

(12) However, replacing ent-L6 with L3 did lead to productive reactions with varying degrees of success. See the SI further details.

(13) (a) Shintani, R.; Okamoto, K.; Hayashi, T. Chem. Lett. 2005, 34, 1294. (b) Yang, M.; Zhang, X.; Lu, X. Org. Lett. 2007, 9, 5131.

(14) (a) Yamamoto, A.; Suginome, M. J. Am. Chem. Soc. 2005, 127, 15706. (b) Daini, M.; Yamamoto, A.; Suginome, M. Asian J. Org. Chem. 2013, 2, 968. 